\title{
A Six-LncRNA Expression Signature Associated with Prognosis of Colorectal Cancer Patients
}

\author{
Jian Zhao ${ }^{\mathrm{a}} \quad$ Jian $\mathrm{Xu}^{\mathrm{a}} \quad$ An-quan Shang ${ }^{\mathrm{b}} \quad$ Rui Zhang ${ }^{\mathrm{a}}$ \\ aDepartment of Colorectal Surgery, Cancer Hospital of China Medical University, Liaoning Cancer \\ Hospital \& Insititute, ShengYang, 'bepartment of Laboratory Medicine, Tongji Hospital of Tongji \\ University School of Medicine, Shanghai, China
}

\author{
Key Words \\ Colorectal cancer $\bullet$ LncRNA $\cdot$ GEO $\bullet$ Prognosis
}

\begin{abstract}
Background/Aims: Colorectal cancer (CRC) is one of the most common malignant tumor with high migration and invasion capacity. Long non-coding RNAs (IncRNAs) have been identified to influence multiple cancers progression through competitively binding microRNAs (miRNAs). In this study, we proposed to develop a IncRNA-based signature for CRC survival outcomes. Methods: LncRNA expression profiles of CRC patients were extracted from the Gene Expression Omnibus (GEO) data sets GSE38832 (training set) and GSE29621 (testing set). Associations between IncRNA expression and CRC disease free survival (DFS) were evaluated through univariate Cox regression analysis, and prognosis signature constructed by combination of weighted IncRNA expression values were obtained through multivariate Cox regression analysis. Robustness of the prognosis signature was evaluated through receiver operating characteristics analysis in the testing set. Results: A weighted prognosis signature of six IncRNAs, including LINC01583, LINC00276, LUNAR1, DKFZp434J0226, SFTA1P and OGFOD3, was yielded from multivariate Cox regression analysis. Samples with significantly different DFS dislayed distinct signatures, indicating considerable predictory accuracy of this expression signature. Conclusion: Robustness of the prognosis signature was evaluated in the testing set through Kaplan-Meier and receiver operating characteristics (ROC) analysis. Furthermore, functional enrichment analysis of IncRNAs suggested significant enrichment of cancer related pathways. Our results revealed the promise of IncRNAs as prognostic biomarkers.




\section{Cellular Physiology Cell Physiol Biochem 2018;50:1882-1890 \begin{tabular}{ll|l} 
and Biochemistry & $\begin{array}{l}\text { DOI: 10.1159/000494868 } \\
\text { Published online: 3 November } 2018\end{array}$ & $\begin{array}{l}\text { (c) } 2018 \text { The Author(s). Published by S. Karger AG, Basel } \\
\text { www.karger.com/cpb }\end{array}$ \\
\hline Zha et al: A Six-LncRNA Expression Signature Associated with Colorectal
\end{tabular} \\ Patients}

\section{Introduction}

Colorectal cancer (CRC) represents the third most common cancer worldwide [1]. Despite the significant advances of custom treatment method, the high migration and invasion capacity have been a bottle-neck for eliminating the mortality, which kept the 5 -year survival rate of CRC under 12\% [2-4]. In addition, several other factors were also identified to influence CRC prognosis, such as health-related quality of life [5], genome stability [6, $7]$, aberrant gene expression [8,9], etc. However, the mechanism underlying CRC survival remains elusive, which impedes the improvement of CRC prognosis.

Long non-coding RNAs (lncRNAs) are defined as transcripts longer than $200 \mathrm{nt}$ in length and without protein-coding potential [10]. In fact, there are a lot more lncRNAs than mRNAs, and recent extensive employment of high-throughput sequencing technologies continuously revealed a plethora of lncRNAs [11]. LncRNAs tend to express in specific tissues and play an important role in regulating gene expression through sponging miRNAs [11, 12]. Multiple studies have unveiled the role of IncRNA in cancer progression [13-17]. For CRC, aberrant expression of several IncRNAs were proved to be significantly associated with its poor prognosis. For example, Iquchi et al. [18] demonstrated that increased lncRNA-ATB level in CRC was significantly associated with greater tumor size, deeper tumor invasion and lymph node metastasis, which could result in poorer prognosis. Down-regulation of lncRNA BANCR that could target $\mathrm{p} 21$ promoted CRC cell proliferation [19]. Up-regulation of IncRNA-CLMAT3 was significantly associated with liver metastasis of CRC and could independently predict CRC prognosis [20].

Identification of prognosis signature based on variety of genome or transcriptome data could promote our understanding about cancer development and improvement of survival rate. Indeed, lots of prognostic signatures have been developed for prediction of cancer prognosis outcomes. For example, Villanueva et al. identified a prognosis signature composed of 36 methylation sites through Illumina HumanMethylation 450K array using random survival forests, which could steadily predicts poor hepatocellular carcinoma survival [21]. Through lncRNA expression profiling of 887 breast cancer patients, Meng et al. developed a four-long non-coding RNA signature for prediction of breast cancer survival [22]. In this study, we aimed to screen IncRNA-based prognosis signature for predicting CRC survival through analysis of IncRNA expression profiles. Univariate Cox regression analysis followed by multivariate Cox regression analysis method was adopted for the identification of CRC survival related lncRNAs. Six-lncRNA signature consisting LINC01583, LINC00276, LUNAR1, DKFZp434J0226, SFTA1P and OGFOD3 was found associated with prognosis. Validation based on the independent datasets confirmed the robustness of the prognosis signature. Furthermore, mRNA genes that co-express with IncRNAs contained signature were closely associated with pathways in cancer. Together, our study suggest a list of biomarkers that hold potential prognostic value, and provide priliminary bioinformatic evidence for understanding their mechanism.

\section{Materials and Methods}

CRC datasets

All of the CRC datasets were obtained from the Gene Expression Omnibus (GEO) with the following criteria: (1) expression values should be detected through the Affymetrix Human Genome U133 Plus 2.0 array; (2) survival information, including survival time and survival status were available online; (3) sample size was > 50. Consequently, two datasets (GSE38832 [23] and GSE29621 [24]) were included in this study. 


\section{Cellular Physiology Cell Physiol Biochem 2018;50:1882-1890 \begin{tabular}{l|l|l} 
and Biochemistry Published online: 3 November 2018 & $\begin{array}{l}\text { (c) } 2018 \text { The Author(s). Published by S. Karger AG, Basel } \\
\text { www.karger.com/cpb }\end{array}$ \\
\hline
\end{tabular} \\ Zhao et al.: A Six-LncRNA Expression Signature Associated with Colorectal Cancer \\ Patients}

\section{Microarray processing and IncRNA screening}

Raw CEL files were downloaded and imported into $R$ programming software through affy [25] Bioconductor package. Probe level expression normalization was conducted through rma function which resulted in log2-based normalized expression values. To screen IncRNA expression profiles, we mapped probesets to the NetAffx Annotation Files (HG-U 133 Plus2 Annotation) and only probesets with a RefSeq transcript ID or/and Ensembl gene ID were retained. LncRNAs were defined as those probesets with RefSeq ID annotated as "NR_" or Ensembl ID annotated as "lincRNA", "processed_transcripts", "non-coding" and "misc_RNA" with removal of probesets annotated as "pseudogenes", "rRNAs", "microRNAs" and other short RNAs.

\section{Statistical analysis}

To explore associations between IncRNA expression and CRC survival, univariate Cox regression analysis was firstly conducted using the survival package of $R$. LncRNAs with logrank test $p$-value $<0.05$ were considered as significance. Multivariate Cox regression analysis was used for the identification of prognosis signature, which is the combination of expression values of significant lncRNAs weighted by their estimated regression coefficients. Samples were divided into two subgroups based on their risk scores obtained through the prognosis signature and Kaplan-Meier analysis was used for the comparison of two groups' survival event. Receiver operating characteristics (ROC) analysis was performed to evaluate the robustness of the prognosis signature.

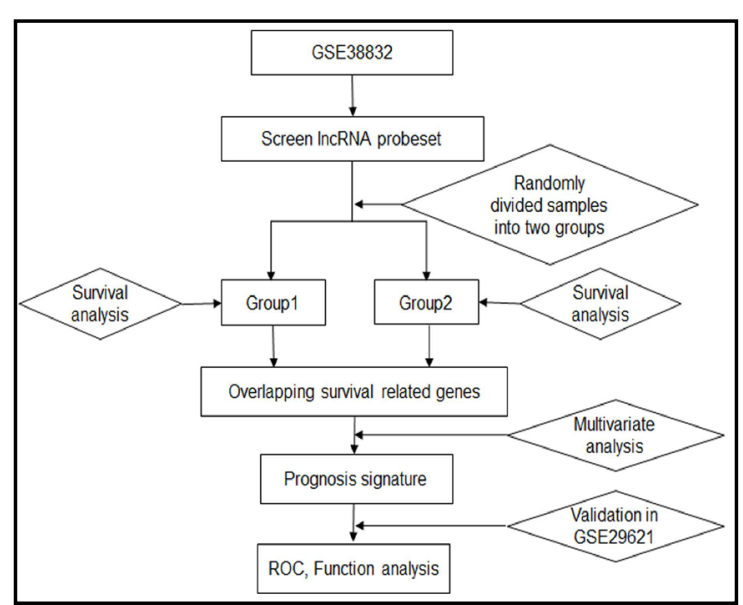

Fig. 1. Workflow of this study. ROC, receiver operating characteristic.

\section{Functional enrichment analysis}

To explore potential functions of IncRNAs contained in the prognosis signature, we obtained their co-expressed mRNA genes through the training set (GSE38832) with the thresholds of $\mathrm{p}$-value $<0.001$ and spearman correlation coefficient $>0.2$ or $<-0.2$. Significantly enriched functions of those mRNAs were obtained through the Database for Annotation, Visualization and Integrated Discovery (DAVID, https://david.ncifcrf.gov/) [26]. Only Gene Ontology (terms) and Kyoto Encyclopedia Genes and Genomes (KEGG) pathways with p-value $<0.05$ were retained. Besides, associations among significant GO terms were explored and visualized through enrichmentMap plug-in [27] of Cytoscape software [28].

\section{Results}

\section{Microarray datasets}

The workflow of this study was shown in Fig. 1. Summary of clinicopathological characteristics of CRC patients in training and testing set was provided in Table 1. Screening of IncRNA profiles resulted in a total of 2, 209 IncRNAs used for the prognosis signature identification.
Table 1. Clinicopathological characteristics of training and testing datasets. Ajcc: American journal of critical care; NA: Not available

\begin{tabular}{|c|c|c|c|}
\hline & & GSE38832 & GSE29621 \\
\hline \multicolumn{4}{|l|}{ Gender } \\
\hline & Male & NA & 40 \\
\hline & Female & NA & 25 \\
\hline \multicolumn{4}{|l|}{ M stage } \\
\hline & Metastasis & NA & 18 \\
\hline & No & NA & 46 \\
\hline & NA & NA & 1 \\
\hline \multicolumn{4}{|c|}{ Differentiation } \\
\hline & $\begin{array}{l}\text { Poorly } \\
\text { Mod }\end{array}$ & $\begin{array}{l}\text { NA } \\
\text { NA }\end{array}$ & $\begin{array}{l}10 \\
51\end{array}$ \\
\hline & Well & NA & 4 \\
\hline \multicolumn{4}{|l|}{ DFS event } \\
\hline & Recurrence & 9 & 9 \\
\hline & No recurrence & 83 & 44 \\
\hline & NA & 30 & 12 \\
\hline \multicolumn{4}{|l|}{ DFS time } \\
\hline & $>36$ months & 49 & 32 \\
\hline & $<36$ months & 43 & 21 \\
\hline & NA & 30 & 12 \\
\hline \multicolumn{4}{|l|}{ OS event } \\
\hline & Dead & NA & 25 \\
\hline \multirow{2}{*}{\multicolumn{4}{|c|}{ OS time }} \\
\hline & & & \\
\hline & $>36$ months & NA & 39 \\
\hline & $<36$ months & NA & 26 \\
\hline \multicolumn{4}{|l|}{ DSS event } \\
\hline & Dead & 28 & NA \\
\hline & Alive & 94 & NA \\
\hline \multicolumn{4}{|l|}{ DSS time } \\
\hline & $>36$ months & 57 & NA \\
\hline \multirow{2}{*}{\multicolumn{4}{|c|}{ Ajcc stage }} \\
\hline & & & \\
\hline Stage1 2 & & & 29 \\
\hline Stage3 4 & & & 36 \\
\hline
\end{tabular}


Zhao et al.: A Six-LncRNA Expression Signature Associated with Colorectal Cancer

Patients

Fig. 2. Prognosis signature in training set. (A) Risk score distribution of samples in GSE38832 set. (B) Kaplan-Meier curves of DFS for the GSE38832 set. (C) Heatmap of IncRNA expression profiles in the GSE38832 set. Rows and columns represent IncRNAs and samples respectively. Color gradient from green to red indicates expression value from low to high.

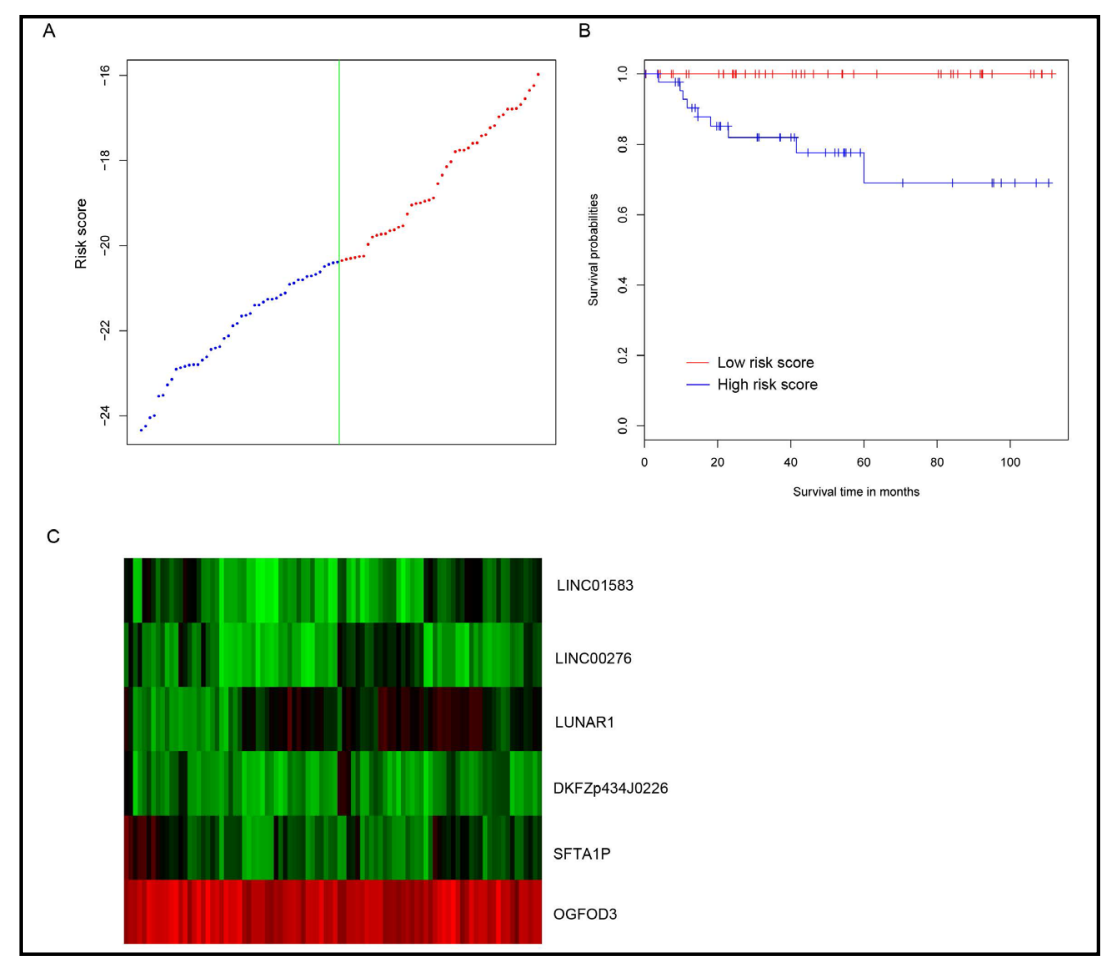

Fig. 3. Prognosis signature in testing set. (A) KaplanMeier curves of DFS for the GSE29621 set. (B) Risk score of samples with different AJCC stage in the GSE29621 set. (C) Receiver operating characteristic analysis of sensitivity and specificity by risk score in predicting DFS in the GSE29621 set.
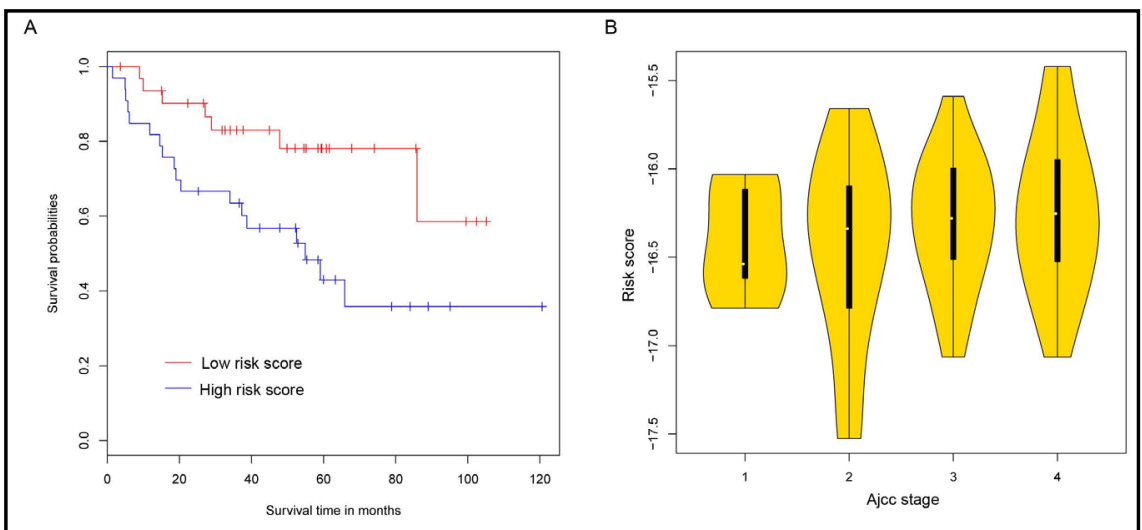

c

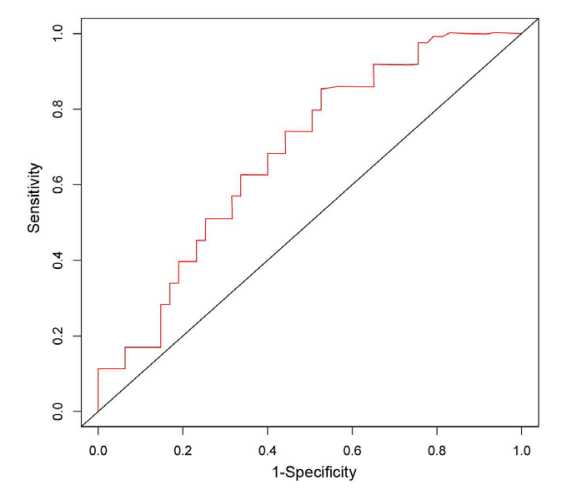




\section{Cellular Physiology Cell Physiol Biochem 2018;50:1882-1890 \begin{tabular}{l|l|l} 
and Biochemistry Published online: 3 November 2018 & $\begin{array}{l}\text { ○ 2018 The Author(s). Published by S. Karger AG, Basel } \\
\text { www.karger.com/cpb }\end{array}$ \\
\hline
\end{tabular} \\ Zhao et al:: A Six-LncRNA Expression Signature Associated with Colorectal Cancer \\ Patients}

\section{Prognosis signature}

GSE38832 set was used as the training set for prognosis signature identification for its relative larger sample size (122 vs. 65). A total of 92 CRC patient samples were retained after filtering out samples with unavailable disease-free survival (DFS) information. Remaining samples were randomly divided into two subgroups with same sample size and univariate Cox regression analysis was performed to explore associations between IncRNA expression and CRC DFS in the two subgroups. Consequently, there were 69 and 261 lncRNAs that were significantly associated with CRC DFS in the two subgroups respectively. Besides, 6 lncRNAs, LINC01583, LINC00276, LUNAR1, DKFZp434J0226, SFTA1P and OGFOD3, were found to be significantly associated with CRC DFS in both of the two subgroups, which were used for the following multivariate Cox regression analysis. Multivariate Cox regression analysis was performed to obtain the estimated regression coefficients of the six lncRNAs for predicting CRC DFS based on their expression values in the 92 CRC patients and patients' DFS information. Finally, the prognosis signature was obtained and the risk score for specific sample could be calculated as follows: (Risk score) $)_{\mathrm{i}}=0.1737^{*}$ LINC01583 $_{\mathrm{i}}+0.9160 * \mathrm{LINC00276}_{\mathrm{i}}+$ $\left(-0.04728^{*}\right.$ LUNAR $\left._{\mathrm{i}}\right)+\left(-0.3086^{*}\right.$ DKFZp434J0226 $\left._{\mathrm{i}}\right)+0.4456^{*}$ SFTA1P $_{\mathrm{i}}+\left(-2.742^{*}\right.$ OGFOD3 $\left._{\mathrm{i}}\right)$.

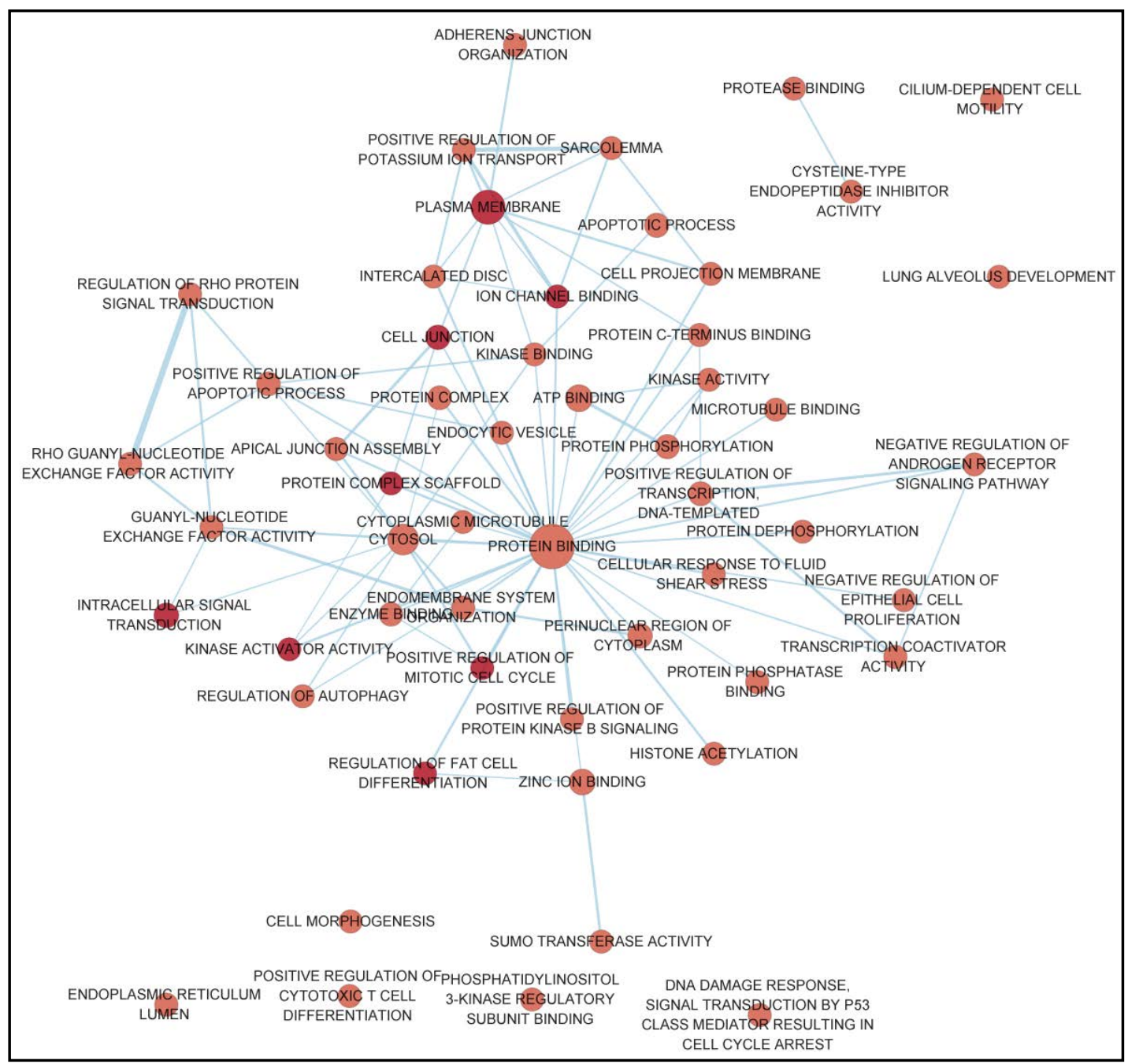

Fig. 4. Functional enrichment analysis of co-express genes of lncRNAs in the prognosis signature. Nodes represent GO terms which are grouped by similarity according to related gene sets. Larger node size indicates more genes contained in the GO term, and thicker line indicates more overlapping genes between two GO terms. 
Zhao et al.: A Six-LncRNA Expression Signature Associated with Colorectal Cancer Patients

LncRNA $_{i}$ in the prognosis signature represents lncRNA expression values in ith CRC samples.

Associations between risk score and CRC DFS in training set

Risk score for every sample in training set was calculated through the prognosis signature.

Fig. 2A illustrated distribution of risk score. Through Fig. 2B, we inferred that risk score is negatively associated with sample's DFS, i.e. higher risk score could predict poorer prognosis $(\mathrm{p}$-value $=0.0011)$. Fig. $2 \mathrm{C}$ showed the expression profile of the six lncRNAs in low risk samples and high risk samples.

\section{Associations between risk score and CRC DFS in testing set}

We calculated risk score for every sample in testing set based on the prognosis signature and divided samples into low risk and high risk group. Kaplan-Meier analysis indicated significant difference in DFS between the two sample groups (Fig. 3A, p-value = 0.0168). Besides, risk score increased with American Joint Committee on Cancer (AJCC) stage development (Fig. 3B), which should indicate reliability of the prognosis. ROC analysis yielded an area under curve (AUC) of 0.683 based on the cut-off of 36 months DFS (Fig. 3C), suggesting the reliability of this prognosis signature in predicting the outcome of 3-year DFS of CRC.

\section{Significantly enriched functions of the six significant IncRNAs}

With the thresholds of p-value $<0.001$ and spearman correlation coefficient $>0.2$ or $<-0.2$, we totally obtained 501 mRNA genes that significantly co-expressed with the six significant lncRNAs. Functional enrichment analysis of the 501 mRNA genes demonstrated significant enrichment of cancer related pathways (Table 1), such as pathways in cancer, MAPK signaling pathways. Furthermore, Fig. 4 illustrated associations among the significantly enriched GO terms. The most significant function group was protein binding related processes, what's more, cell activity regulation processes were also obtained.

\section{Discussion}

Due to high migration and invasion capacity, the 5-year survival rate of CRC patients is low. Accurate predictions of prognosis is of critical importance for personalized therapeutic regime for CRC patients. In this study, we identified a six lncRNA-based prognosis signature for CRC, which was porved to reliably predict CRC DFS in robustness evaluation.

LncRNAs are frequently found to be aberrantly expressed in cancers, yet only a few studies developed IncRNA-based prognosis signature [29, 30]. In this study, we constructed the prognosis signature for predicting CRC DFS based on the resulting risk score of every sample, whose lncRNA profiling data was obtained from previous published studies. Consequenly, high risk score was found to be closely associated with poorer CRC prognosis in both training set as well as testing set, which should indicate the robustness of our prognosis signature. In addition, risk score become higher when samples are with higher AJCC stage (Fig. 3B). The AJCC staging system was developed by the American Joint Committee on Cancer which mainly used for describing cancer progression extent. AJCC stage was widely used for cancer survival prediction with higher AJCC stage indicates poorer survival [31-33]. Therefore, it can be inferred that AJCC stage is highly correlated with risk scores (Table 2). 


\section{Cellular Physiology Cell Physiol Biochem 2018;50:1882-1890 \begin{tabular}{ll|l} 
DOI: $10.1159 / 000494868$ & O 2018 The Author(s). Published by S. Karger AG, Basel \\
and Biochemistry & Published online: 3 November 2018 www.karger.com/cpb \\
\cline { 2 - 3 }
\end{tabular} \\ Zhao et al.: A Six-LncRNA Expression Signature Associated with Colorectal Cancer Patients}

The prognosis signature consists of six IncRNA expression values weighted by estimated regression coefficients. Expression of SFTA1P was positively associated with risk score (regression coefficient $=0.4456$ ), which indicated that higher SFTA1P should predict poorer CRC prognosis. In lung cancer, SFTA1P was down-regulated, which could induce upregulation of hnRNP-U-GADD45A followed by promotion of apoptosis and increasing of cisplatin chemosensitivity [34]. Besides, Zhang et al. also found that SFTA1P could suppress lung adenocarcinoma cell migration and invasion [35] and similar functions were identified in gastric cancer [36]. That our study provide contradictory results may be due to the types of cancer in study, which warrants further studies to validate the rrole of SFTA1P in CRC. LUNAR1 (leukemia-associated non-coding IGF1R activator RNA 1), was found to have slight negative correlation with risk score (regression coefficient $=-0.04728$ ). Currently, the function of LUNAR1 has only been reported in leukemia, in which it promoted leukemia cell proliferation and predicts poor progosis [37], and its roles in CRC progression requires indepth investigatios.

\section{Conclusion}

In conclusion, we identified a six lncRNA-based CRC prognosis signature for predicting DFS. The expressio pattern reliably separates CRC samples with poor prognosis from those with good prognosis. Functional analysis suggested significant enrichment of cancer related processes. This correlatio should be helpful for decision making for designing therapies for CRC patients. Although our study provide a list of promising candidates with prognostic value, further studies are still needed to confirm their functions in CRC to complement the lack of functional validation in this study.

\section{Acknowledgements}

This work was supported by Clinical Capability Construction Project for Liaoning Provincial Hospitals (LNCCC-D44-2015).

\section{Disclosure statement}

The authors declare no competing interests.

\section{References}

1 Matusiewicz M, Kosieradzaka I, Niemiec T, Grodzik M, Antushevich H, Strjny B, and Golebiewska: In vitro Influence of Extracts from Snail Helix aspersa Muller on the Colon Cancer Cell Line Caco-2. Int J Mol Sci 2018;19:1064.

-2 Kalyan, A, Kircher S, Shah H, Mulcahy M, and Benson A: Updates on immunotherapy for colorectal cancer. J Gastrointest Oncol 2018;9:160-169.

-3 Sun Y, Zheng Z, Li H, Zhang H, Ma F: ANRIL is associated with the survival rate of patients with colorectal cancer, and affects cell migration and invasion in vitro. Mol Med Rep 2016;14:1714-1720.

-4 Qi P, Xu M, Ni S, Shen X, Wei P, Huang D, Tan C, Sheng W, Zhou X, and Du X: Down-regulation of ncRAN, a long non-coding RNA, contributes to colorectal cancer cell migration and invasion and predicts poor overall survival for colorectal cancer patients. Mol Carcinog 2015;54:42-50.

$>5$ Fournier E, Jooste V, Woronoff A, Quipourt V, Bouvier A, and Mercier M: Health-related quality of life is a prognostic factor for survival in older patients after colorectal cancer diagnosis: A population-based study. Dig Liver Dis 2016;48:87-93. 


\section{Cellular Physiology Cell Physiol Biochem 2018;50:1882-1890 \begin{tabular}{l|l|l|l|} 
DOI: 10.1159/000494868 & (c) 2018 The Author(s). Published by S. Karger AG, Basel
\end{tabular} and Biochemistry Published online: 3 November 2018 www.karger.com/cpb}

Zhao et al.: A Six-LncRNA Expression Signature Associated with Colorectal Cancer

Patients

6 Kang S, Na Y, Joung S, Lee S, Oh S, Min B: The significance of microsatellite instability in colorectal cancer after controlling for clinicopathological factors. Medicine (Baltimore) 2018;97:e0019.

7 Gkekas I, Novotny J, Pecen L, Strigard K, Palmqvist R, and Gunnarsson U: Microsatellite Instability as a Prognostic Factor in Stage II Colon Cancer Patients, a Meta-Analysis of Published Literature. Anticancer Res 2017;37:6563-6574.

8 Zhu Z and Dong W: Overexpression of HHLA2, a member of the B7 family, is associated with worse survival in human colorectal carcinoma. Onco Targets Ther 2018;11:1563-1570.

-9ee S J, Lee J, Park S H, Park J O, Kim Y, Mang W K, Park Y S, and Kim S T: c-MET Overexpression in Colorectal Cancer: A Poor Prognostic Factor for Survival. Clin Colorectal Cancer 2018;17:165-169.

10 Morris K.V, and Mattick J.S: The rise of regulatory RNA. Nat Rev Genet 2014; 15:423-437.

11 Schmitt A M and Chang H Y: Long Noncoding RNAs in Cancer Pathways. Cancer Cell 2016;29:452-463.

12 Thomson D W and Dinger M E: Endogenous microRNA sponges: evidence and controversy. Nat Rev Genet 2016;17:272-283.

13 Martens-Uzunova E S, Bottcher R, Crocs C M, Jester G, Visakorpi T, and Calin G.A: Long noncoding RNA in prostate, bladder, and kidney cancer. Eur Urol 2014;65:1140-1151.

14 Bolton E M, Tuzova A T, Walsh A L, Lynch T, and Perry A S: Noncoding RNAs in prostate cancer: the long and the short of it. Clin Cancer Res 2014;20:35-43.

15 Roth A and Diederichs S: Long Noncoding RNAs in Lung Cancer. Curr Top Microbiol Immunol 2016;394:57-110.

16 Zhang H, Chen Z, Wang X, Hang Z, He Z, and Chen Y: Long non-coding RNA: a new player in cancer. J Hematol Oncol 2013;6:37.

17 Ylipaa A, Kivinummi K, Ambala M, Latonen L, Scaravilli M, Kartasalo K, Leanne S.P, Karakurt S, Seppälä J, Yli-Harja O, Tammela TL, Zhang W, Visakorpi T, Nykter M: Transcriptome Sequencing Reveals PCAT5 as a Novel ERG-Regulated Long Noncoding RNA in Prostate Cancer. Cancer Res 2015;75:4026-4031.

-18 Iguchi T, Uchi R, Nambara S, Saito T, Komatsu H, Hirata H, Ueda M, Sakimura S, Takano Y, Shinden Y, Eguchi $\mathrm{H}$, Sugimachi K, Maehara Y, Mimori K: A long noncoding RNA, lncRNA-ATB, is involved in the progression and prognosis of colorectal cancer. Anticancer Res 2015; 35:1385-1388.

19 Shi Y, Liu Y, Wang J, Jie D, Yun T, Li W, Wang K, and Feng J: Downregulated Long Noncoding RNA BANCR Promotes the Proliferation of Colorectal Cancer Cells via Downregualtion of p21 Expression. PLoS One 2015;10:e0122679.

20 Ye LC, Ten L, Quiz JJ, Zhu DX, Chen T, Chang WJ, Lv SX, and Xu J: Aberrant expression of long noncoding RNAs in colorectal cancer with liver metastasis. Tumour Biol 2015;36:8747-8754.

-21 Villanueva A, Portal A, Sayols S, Battiston C, Hoshida Y, Gonzalez J M, Imbeaud S, Letouze E, HernandezGea V, Cornella H, Pinyol R, Solé M, Fuster J, Zucman-Rossi J, Mazzaferro V, Esteller M, Llovet JM: DNA methylation-based prognosis and epidrivers in hepatocellular carcinoma. Hepatology 2015;61: 1945-1956.

22 Meng J, Lo P, Zhang Q Yang Z, and Fu S: A four-long non-coding RNA signature in predicting breast cancer survival. J Exp Clin Cancer Res 2014;33:84.

-23 Tripathi M K, Deanne N G, Zhu J, An H, Mina S, Wang X, Padmanabhan S, Shi Z. Prodduturi N, Ciombor K K,Chen X, Washington MK, Zhang B, Beauchamp RD: Nuclear factor of activated T-cell activity is associated with metastatic capacity in colon cancer. Cancer Res 2014;74:6947-6957.

24 Chen D T, Hernandez J M, Shibata D, McCarthy S M, Humphreies L A, Clark W, Elahi A, Gruidl M, Coppola D, and Yeatman T: Complementary strand microRNAs mediate acquisition of metastatic potential in colonic adenocarcinoma. J Gastrointest Surg 2012;16:905-912.

-25 Gautier L, Cope L, Bolstad B M, and Irizarry R: affy--analysis of Affymetrix GeneChip data at the probe level. Bioinformatics 2004;20:307-315.

26 Huang D W, Sherman B, Tan Q, Kit J, Lou D, Bryant D, Guo Y, Stephens R, Baseler M, Lane C, Lempicki A: DAVID Bioinformatics Resources: expanded annotation database and novel algorithms to better extract biology from large gene lists. Nucleic Acids Res 2007;35(Web Server issue):W169-175.

27 Merico D, Isserlin R, Stueker O, Emili A, and Bader G.D: Enrichment map: a network-based method for gene-set enrichment visualization and interpretation. PLoS One 2010;5:e13984.

28 Su G, Morris J H, Demchak B, and Bader G D: Biological network exploration with Cytoscape 3. Curr Protoc Bioinformatics 2014;47:8.13.1-24.

29 Hu Y, Chen H Y, Yu C Y, Zu J, Wang J L, Qian J, Zhang X, and Fang J Y: A long non-coding RNA signature to improve prognosis prediction of colorectal cancer. Oncotarget 2014;5:2230-2242. 


\section{Cellular Physiology Cell Physiol Biochem 2018;50:1882-1890

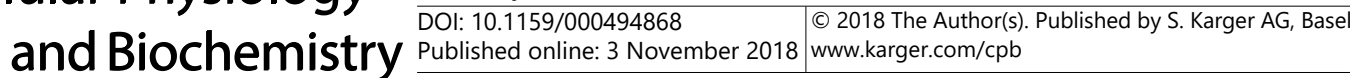 \\ Zhao et al.: A Six-LncRNA Expression Signature Associated with Colorectal Cancer Patients}

30 Fan Q, and Liu B: Discovery of a novel six-long non-coding RNA signature predicting survival of colorectal cancer patients. J Cell Biochem 2018;119:3574-3585.

-31 Kreppel M, Cheer M, Meyer M, Steiner M, Wedemeyer I, Drebber U, Semru R, Odenthal M, Zoller J.E, Guntina-Licius O, Büttner R, Beutner D: Comparison of TNM-based stage grouping versus UICC/AJCC stage grouping (7th edition) in malignant parotid gland tumors. Oral Oncol 2013;49:903-910.

-32 Yuan L, Lou X, Lu X, Hang B, and Cai Q: Liver resection for intrahepatic cholangiocarcinoma in AJCCstage : An evaluation of the survival benefit and prognostic accuracy of current AJCC staging system on N and M classification. Oncol Rep 2016;36:2663-2672.

-33 Kobayashi H, K. Kotake, and K. Sugihara: Prognostic scoring system for stage IV colorectal cancer: is the AJCC sub-classification of stage IV colorectal cancer appropriate? Int J Clin Oncol 2013;18:696-703.

-34 Li L, Tin J Y, He F Z, Hang M S, Zhu T, Gai Y F, Chen Y X, Zhou D B, Chen X, Sun L Q, Zhang W, Zhou H H, Liu Z Q: Long noncoding RNA SFTA1P promoted apoptosis and increased cisplatin chemosensitivity via regulating the hnRNP-U-GADD45A axis in lung squamous cell carcinoma. Oncotarget 2017;8:97476-97489.

-35 Zhang H, Doing Y Q, Xia R, Wei C, Shi X, and Nie F: The pseudogene-derived long noncoding RNA SFTA1P is down-regulated and suppresses cell migration and invasion in lung adenocarcinoma. Tumour Biol 2017;39:1010428317691418.

-36 Ma H, Ma T, Chen M, Zhou Z, and Zhang Z: The pseudogene-derived long noncoding RNA SFTA1P suppresses cell proliferation, migration and invasion in gastric cancer. Biosci Rep DOI: 10.1042/ BSR20171193.

-37 Peng W. and J. Feng: Long noncoding RNA LUNAR1 associates with cell proliferation and predicts a poor prognosis in diffuse large B-cell lymphoma. Biomed Pharmacother 2016;77:65-71. 